MSC $80 \mathrm{~A} 23$

\title{
Solvability of hyperbolic systems with distributed parameters on the graph in the weak formulation
}

\author{
V. V. Provotorov ${ }^{1}$, S. M. Sergeev ${ }^{2}$, A. A. Part ${ }^{3}$ \\ 1 Voronezh State University, 1, Universitetskaya pl., Voronezh, \\ 394006, Russian Federation \\ 2 Peter Great Saint Petersburg State Polytechnic University, 29, ul. Polytechicheskaya, \\ St. Petersburg, 195251, Russian Federation \\ 3 Air Force Academy named after professor N. E. Zhukovsky and Y. A. Gagarin, \\ 54a, ul. Starikh Bol'shevikov, Voronezh, 396064, Russian Federation
}

For citation: Provotorov V. V., Sergeev S. M., Part A. A. Solvability of hyperbolic systems with distributed parameters on the graph in the weak formulation. Vestnik of Saint Petersburg University. Applied Mathematics. Computer Science. Control Processes, 2019, vol. 15, iss. 1, pp. 107-117. https://doi.org/10.21638/11702/spbu10.2019.108

We investigate weak solvability of the initial-boundary value problem for the hyperbolic equation with distributed parameters on the oriented limited graph and regional conditions of the third type. The spatial variable is changed to the limited oriented graph. The differential ratio was determined on the edges of the graph without the end points. Internal differential ratio graph nodes are replaced by generic terms of Kirchhoff. The differential ratio in internal knots of the graph is replaced with the generalized conditions of Kirchhoff (in applications the balance relations). The space of the admission weak solutions consists of functions with bearer on the graph belonging the space of Sobolev and satisfy the generalized conditions in "limits" sense. Idea analysis of initial-boundary value problem remains the classic: selected functional space with a special base (system of generalized eigenfunctions of an elliptic operator task), which consider the initial-boundary value problem; for approximations to the weak problem solving (the Faedo-Galerkin approximations) establishes a priori estimates of the energy type inequalities; shows weak compactness the Faedo-Galerkin approximation family. Previously initial-boundary value problem is seen in the space of functions with the second generalized derivatives and for such a task is proved equivalent energy inequality. From this it follows: a) convergence of Faedo-Galerkin approximation to the weak solution; b) approximation of the original problem of a course-measuring system of ordinary differential equations. In the work point out the path approximation of the original problem-dimensional system, which allows you to get the theorem on approximation used in the tasks of an applied character. Presents light conditions on the original task data, guaranteeing the weak solvability task. These conditions often occur in applications. Considered by the task and the approach to its analysis of enough is frequently often used in the mathematical description of the oscillation processes in technical designs-net, also in examining wave phenomena in hydronet. The results are fundamental in the study of problems of optimum (of optimum control)of network industrial construction.

Keywords: graph, hyperbolic equation initial-boundary problem, a priori estimates, the weak solutions.

Introduction. Examines the weak solutions of initial-boundary value problem for a hyperbolic equation of second order with distributed parameters on an arbitrary oriented graph. Such solutions are determined by using the integral identities, substitute an equation, initial and boundary conditions. It includes point out the space in which it is proposed to find a weak solution and provides conditions for the solvability of such a

(C) Санкт-Петербургский государственный университет, 2019 
task. The central idea, which all the contents of the present work consists in applying used in monographs O. A. Ladyzhenskaya [1, pp. 146, 196] approaches to the analysis of evolutionary initial-boundary value problems and synthesis of famous classical statements the existence of weak solutions of the equation of hyperbolic type, based on the evidence of weak compactness many Faedo-Galerkin approximations [1, p. 196] (see also [2, p. 132]). Are considered homogeneous boundary conditions of the third type (mixed boundary conditions), more frequent in applications.

The results are fundamental in the study of problems of optimum control of network industrial construction.

Basic concepts and designations, the space of functions on the graph. In section contains a few proposals that are used in the study. Designations are used, taken in $[3,4]: \Gamma$ is the limited geometric graph; the ribs $\gamma$ of the graph are parameterized $[0,1] ; \partial \Gamma$ is many boundary knots $\zeta ; J(\Gamma)$ is many internal knots $\xi$, with this settings $x_{\zeta}$ and $x_{\xi}$ knots $\zeta$ and $\xi$ ribs $\gamma$ take the values 0 or 1 depending on the parameterized $\gamma$ of $[0,1] ; \Gamma_{0}$ is the combination of all ribs that do not contain ending points; $\Gamma_{t}=\Gamma_{0} \times(0, t)$, $\partial \Gamma_{t}=\partial \Gamma \times(0, t)(t \in[0, T])$. Throughout the work uses Lebesgue integral for the field $\Gamma_{0}$ or $\Gamma_{t}: \int_{\Gamma_{0}} f(x) d x=\int_{\Gamma} f(x) d x=\sum_{\gamma} f(x)_{\gamma} d x$ or $\int_{\Gamma_{t}} f(x, t) d x d t=\sum_{\gamma_{t}} f(x, t)_{\gamma} d x d t, f(\cdot)_{\gamma}$ is narrowing function $f(\cdot)$ on an ribs $\gamma$.

Relabel $L_{2}(\Gamma)$ the space of integrable on $\Gamma$ functions with square (similarly, you enter a space $L_{2}\left(\Gamma_{T}\right)$ and $\left.L_{1}\left(\Gamma_{T}\right)\right) ; W_{2}^{1}(\Gamma)$ is the space of functions from $L_{2}(\Gamma)$ with generalized derivative first-order also from $L_{2}(\Gamma) ; W_{2}^{1}\left(\Gamma_{T}\right)$ is the space of functions from $L_{2}\left(\Gamma_{T}\right)$ with all the generalized derivatives first-order of $L_{2}\left(\Gamma_{T}\right) ; L_{2,1}\left(\Gamma_{T}\right)$ is the space of functions from $L_{1}\left(\Gamma_{T}\right)$ with norm

$$
\|u\|_{L_{2,1}\left(\Gamma_{T}\right)}=\int_{0}^{T}\left(\int_{\Gamma} u^{2}(x, t) d x\right)^{1 / 2} d t .
$$

Remark 1. It should be noted what elements $W_{2}^{1}\left(\Gamma_{T}\right)$ defined on each section of the cylinder $\Gamma_{T}$ plane $t=t_{0}$ as elements of the space $L_{2}(\Gamma)$ and are continuous on $t$ in the norm $L_{2}(\Gamma)$ (see also [1, p. 70]).

In space $W_{2}^{1}(\Gamma)$ consider the bilinear form

$$
l(\mu, \nu)=\int_{\Gamma}\left(a(x) \frac{d \mu(x)}{d x} \frac{d \nu(x)}{d x}+b(x) \mu(x) \nu(x)\right) d x
$$

with fixed measurable and limited to $\Gamma_{0}$ coefficients $a(x), b(x)$.

Occurs following approval.

Lemma 1 [2, p. 92]. Let the function $u(x) \in W_{2}^{1}(\Gamma)$ such that $\ell(u, \nu)-\int_{\Gamma} f(x) \eta(x) d x=$ 0 for any $\eta(x) \in W_{2}^{1}(\Gamma)\left(f(x) \in L_{2}(\Gamma)\right.$ is fixed function). Then for any rib $\gamma \subset \Gamma$ the narrowing $a(x)_{\gamma} \frac{d u(x)_{\gamma}}{d x}$ continuously in the end points of the rib $\gamma$.

Statement of lemma 1 implies that space $W_{2}^{1}(\Gamma)$ contains many $\Omega_{a}(\Gamma)$ functions $u(x) \in C(\Gamma)(C(\Gamma)$ is the space of continuous functions on $\Gamma)$ for which each $\gamma \subset \Gamma$ the narrowing $a(x)_{\gamma} \frac{d u(x)_{\gamma}}{d x}$ continuously in the end points $\gamma$ and the ratio of

$$
\sum_{\gamma \in R(\xi)} a(1)_{\gamma} \frac{d u(1)_{\gamma}}{d x}=\sum_{\gamma \in r(\xi)} a(0)_{\gamma} \frac{d u(0)_{\gamma}}{d x}
$$

for internal knots $\xi \in \gamma$ (in here $R(\xi)$ and $r(\xi)$ is of the ribs accordingly oriented "to knot $\xi$ " and "from knot $\xi$ "). The enclosure of the many $\Omega_{a}(\Gamma)$ in norm $W_{2}^{1}(\Gamma)$ relabel $W_{a}^{1}(\Gamma)$; obviously $W_{a}^{1}(\Gamma) \subset W_{2}^{1}(\Gamma)$. 
Let further $\Omega_{a}\left(\Gamma_{T}\right)$ are many of functions $u(x, t) \in W_{2}^{1}\left(\Gamma_{T}\right)$, whose traces are defined in sections of the field $\Gamma_{T}$ the plane $t=t_{0}\left(t_{0} \in[0, T]\right)$ as a function of class $W_{a}^{1}(\Gamma)$ (see Remark 1) and satisfy a ratios

$$
\sum_{\gamma \in R(\xi)} a(1)_{\gamma} \frac{\partial u(1, t)_{\gamma}}{\partial x}=\sum_{\gamma \in r(\xi)} a(0)_{\gamma} \frac{\partial u(0, t)_{\gamma}}{\partial x}
$$

for all knots $\xi \in J(\Gamma)$. The enclosure of the many $\Omega_{a}\left(\Gamma_{T}\right)$ in norm $W_{2}^{1}\left(\Gamma_{T}\right)$ relabel $W_{0}^{1}\left(a, \Gamma_{T}\right), W_{a}^{1}\left(\Gamma_{T}\right) \subset W_{2}^{1}\left(\Gamma_{T}\right)$.

Statement of the problem. In the space $W_{a}^{1}\left(\Gamma_{T}\right)$ is considered the third initialboundary value problem, boundary conditions which are reduced to a uniform

$$
\begin{gathered}
\frac{\partial^{2} u(x, t)}{\partial t^{2}}-\frac{\partial}{\partial x}\left(a(x) \frac{\partial u(x, t)}{\partial x}\right)+b(x) u(x, t)=f(x, t), \\
\left.u\right|_{t=0}=\varphi(x),\left.\frac{\partial u}{\partial t}\right|_{t=0}=\psi(x), \quad x \in \Gamma, \\
\left(a(x) \frac{\partial u(x, t)}{\partial x}+\sigma u(x, t)\right)_{\partial \Gamma}=0, \quad 0 \leqslant t \leqslant T,
\end{gathered}
$$

here $\sigma$ is the given constant, $\varphi(x) \in W_{a}^{1}(\Gamma), \psi(x) \in L_{2}(\Gamma), f(x, t) \in L_{2,1}\left(\Gamma_{T}\right)$. For coefficients $a(x)$ and $b(x)$ are the assumptions place

$$
0<a_{*} \leqslant a(x) \leqslant a^{*}, \quad|b(x)| \leqslant b^{*}, x \in \Gamma .
$$

Definition. A weak solution of a class $W_{2}^{1}\left(\Gamma_{T}\right)$ the initial-boundary value problem (1)-(3) is a function $u(x, t) \in W_{a}^{1}\left(\Gamma_{T}\right)$ equal to $\varphi(x)$, when $t=0$ and satisfies the integral identity

$$
\begin{aligned}
& \int_{\Gamma_{T}}\left(-\frac{\partial u(x, t)}{\partial t} \frac{\partial \eta(x, t)}{\partial t}+a(x) \frac{\partial u(x, t)}{\partial x} \frac{\partial \eta(x, t)}{\partial x}+b(x) u(x, t) \eta(x, t)\right) d x d t+ \\
& +\left.\int_{0}^{T} \sum_{\zeta \in \partial \Gamma} \sigma u(x, t) \eta(x, t) d t\right|_{x=x_{\zeta} \subset \zeta}=\int_{\Gamma} \psi(x) \eta(x, 0) d x+\int_{\Gamma_{T}} f(x, t) \eta(x, t) d x d t,
\end{aligned}
$$

when any $\eta(x, t) \in \widetilde{W}_{a}^{1}\left(\Gamma_{T}\right)$ (elements of space $\widetilde{W}_{a}^{1}\left(\Gamma_{T}\right)$ belong to $W_{a}^{1}\left(\Gamma_{T}\right)$ and meet the equality $\eta(x, T)=0)$.

The preliminary discourse, a priori estimates. Show that for solutions $u(x, t)$ of initial-boundary value problem (1)-(3) in the space $W_{a}^{2}\left(\Gamma_{T}\right)$ (in here $W_{a}^{2}\left(\Gamma_{T}\right)$ is the space of functions $u(x, t)$ from $W_{a}^{1}\left(\Gamma_{T}\right)$, with generalized derivatives $\frac{\partial^{2} u(x, t)}{\partial x^{2}}, \frac{\partial^{2} u(x, t)}{\partial t^{2}}$ from $L_{2}\left(\Gamma_{T}\right)$ ) you can give the a priori assessment through the initial data $\varphi(x), \psi(x), f(x, t)$ the problem (1)-(3).

Multiply equation (1) on $2 \frac{\partial u(x, t)}{\partial t}$ and integrate in the area $\Gamma_{t}$ :

$$
\begin{gathered}
\int_{\Gamma_{t}} 2\left(\frac{\partial^{2} u(x, t)}{\partial t^{2}} \frac{\partial u(x, t)}{\partial t}-\frac{\partial}{\partial x}\left(a(x) \frac{\partial u(x, t)}{\partial x}\right) \frac{\partial u(x, t)}{\partial t}+b(x) u(x, t) \frac{\partial u(x, t)}{\partial t}\right) d x d t= \\
=\int_{\Gamma_{t}} 2 f(x, t) \frac{\partial u(x, t)}{\partial t} d x d t .
\end{gathered}
$$

The second member the left part (6) transform the integration by parts

$$
\int_{\Gamma_{t}} 2\left(\frac{\partial^{2} u(x, t)}{\partial t^{2}} \frac{\partial u(x, t)}{\partial t}+a(x) \frac{\partial u(x, t)}{\partial x} \frac{\partial^{2} u(x, t)}{\partial t \partial x}+b(x) u(x, t) \frac{\partial u(x, t)}{\partial t}\right) d x d t-
$$




$$
-\left.\int_{0}^{t} \sum_{\zeta \in \partial \Gamma} 2 a(x) \frac{\partial u(x, t)}{\partial x} \frac{\partial u(x, t)}{\partial t} d t\right|_{x=x_{\zeta} \in \zeta}=\int_{\Gamma_{t}} 2 f(x, t) \frac{\partial u(x, t)}{\partial t} d x d t,
$$

$x_{\zeta}$ takes the value corresponding to the parameterized of the rib $\gamma$, which belong to boundary node $\zeta$.

Given the ratio of (3), we get

$$
\begin{gathered}
\int_{\Gamma_{t}} 2\left(\frac{\partial^{2} u(x, t)}{\partial t^{2}} \frac{\partial u(x, t)}{\partial t}+a(x) \frac{\partial u(x, t)}{\partial x} \frac{\partial^{2} u(x, t)}{\partial t \partial x}+b(x) u(x, t) \frac{\partial u(x, t)}{\partial t}\right) d x d t+ \\
+\left.\int_{0}^{t} \sum_{\zeta \in \partial \Gamma} 2 \sigma u(x, t) \frac{\partial u(x, t)}{\partial t} d t\right|_{x=x_{\zeta} \in \zeta}=\int_{\Gamma_{t}} 2 f(x, t) \frac{\partial u(x, t)}{\partial t} d x d t .
\end{gathered}
$$

Relabel $y(t)=\int_{\Gamma}\left(\left(\frac{\partial u(x, t)}{\partial t}\right)^{2}+a(x)\left(\frac{\partial u(x, t)}{\partial x}\right)^{2}\right) d x$ and after simple transformation come to ratios

$$
\begin{gathered}
\int_{\Gamma_{t}} 2\left(\frac{\partial^{2} u(x, t)}{\partial t^{2}} \frac{\partial u(x, t)}{\partial t}+a(x) \frac{\partial u(x, t)}{\partial x} \frac{\partial^{2} u(x, t)}{\partial t \partial x}+b(x) u(x, t) \frac{\partial u(x, t)}{\partial t}\right) d x d t+ \\
+\left.\int_{0}^{t} \sum_{\zeta \in \partial \Gamma} 2 \sigma u(x, t) \frac{\partial u(x, t)}{\partial t} d t\right|_{x=x_{\zeta} \epsilon \zeta}=y(t)-y(0)+\int_{\Gamma_{t}} 2 b(x) u(x, t) \frac{\partial u(x, t)}{\partial t} d x d t+ \\
+\left.\sum_{\zeta \in \partial \Gamma} \sigma u^{2}(x, t)\right|_{x=x_{\zeta} \in \zeta}-\left.\sum_{\zeta \in \partial \Gamma} \sigma u^{2}(x, 0)\right|_{x=x_{\zeta} \in \zeta}=2 \int_{\Gamma_{t}} f(x, t) \frac{\partial u(x, t)}{\partial t} d x d t .
\end{gathered}
$$

Set the estimate for $\left.\sum_{\zeta \in \partial \Gamma} \sigma u^{2}(x, t)\right|_{x=x_{\zeta} \in \zeta}$. To do this, fix any boundary rib $\gamma$ with boundary $\zeta$ and internal $\xi$ knots and will perform the subsequent reasoning in the domain $\varpi=\left\{(x, t): x_{\zeta} \leqslant x \leqslant \delta, 0 \leqslant t \leqslant T, x_{\zeta}<\delta \leqslant x_{\xi}\right\}$ (the number $x_{\zeta}$ and $x_{\xi}$ define parameterized rib $\gamma$, number $\delta$ is the distance the point $x \in \gamma$ from boundary knots $\zeta$ ). For any function $u(x, t) \in W_{a}^{2}\left(\Gamma_{T}\right),(x, t) \in \varpi$, have a place of equality

$$
u(x, t)-u\left(x_{\zeta}, t\right)=\int_{x_{\zeta}}^{x} \frac{\partial u\left(x_{1}, t\right)}{\partial x_{1}} d x_{1}, \quad u(x, t)-u(x, 0)=\int_{0}^{t} \frac{\partial u(x, \tau)}{\partial \tau} d \tau,
$$

from which are derived the following assessment:

$$
\begin{gathered}
u^{2}\left(x_{\zeta}, t\right) \leqslant 2\left(u^{2}(x, t)+\left(\int_{x_{\zeta}}^{x} \frac{\partial u\left(x_{1}, t\right)}{\partial x_{1}} d x_{1}\right)^{2}\right), \\
u^{2}(x, t) \leqslant 2\left(u^{2}(x, 0)+\left(\int_{0}^{t} \frac{\partial u(x, \tau)}{\partial \tau} d \tau\right)^{2}\right),
\end{gathered}
$$

and hence the assessment

$$
\begin{gathered}
u^{2}\left(x_{\zeta}, t\right) \leqslant 2\left(2\left(u^{2}(x, 0)+\left(\int_{0}^{t} \frac{\partial u(x, \tau)}{\partial \tau} d \tau\right)^{2}\right)+\left(\int_{x_{\zeta}}^{x} \frac{\partial u\left(x_{1}, t\right)}{\partial x_{1}} d x_{1}\right)^{2}\right)= \\
=4 u^{2}(x, 0)+4\left(\int_{0}^{t} \frac{\partial u(x, \tau)}{\partial \tau} d \tau\right)^{2}+2\left(\int_{x_{\zeta}}^{x} \frac{\partial u\left(x_{1}, t\right)}{\partial x_{1}} d x_{1}\right)^{2}
\end{gathered}
$$


in the surroundings boundary knots $\zeta$, if enough small $\delta$. Since the right part of the resulting in equality is the sum of nonnegative members, this assessment can be extended to all rib $\gamma$, take into account

$$
\left(\int_{0}^{t} \frac{\partial u(x, \tau)}{\partial \tau} d \tau\right)^{2} \leqslant t \int_{0}^{t}\left(\frac{\partial u(x, \tau)}{\partial \tau}\right)^{2} d \tau, \quad\left(\int_{x_{\zeta}}^{x} \frac{\partial u\left(x_{1}, t\right)}{\partial x_{1}} d x_{1}\right)^{2} \leqslant\left|\delta-x_{\zeta}\right| \int_{\gamma}\left(\frac{\partial u\left(x_{1}, t\right)}{\partial x_{1}}\right)^{2} d x_{1}
$$

and identifying, through $\epsilon_{\delta}=2\left|\delta-x_{\zeta}\right|$ :

$$
u^{2}\left(x_{\zeta}, t\right) \leqslant \epsilon_{\delta} \int_{\gamma}\left(\frac{\partial u\left(x_{1}, t\right)}{\partial x_{1}}\right)^{2} d x_{1}+4 u^{2}(x, 0)+4 t \int_{0}^{t}\left(\frac{\partial u(x, \tau)}{\partial \tau}\right)^{2} d \tau .
$$

The resulting inequality after integration along $\gamma(|\gamma|=1)$ takes the following form:

$$
u^{2}\left(x_{\zeta}, t\right) \leqslant \epsilon_{\delta} \int_{\gamma}\left(\frac{\partial u\left(x_{1}, t\right)}{\partial x_{1}}\right)^{2} d x_{1}+4 \int_{\gamma} u^{2}(x, 0) d x+4 t \int_{\gamma_{t}}\left(\frac{\partial u(x, \tau)}{\partial \tau}\right)^{2} d \tau d x
$$

(here $\left.\gamma_{t}=\gamma \times(0, t)\right)$. Summarizing the latest on all boundary ribs $\gamma$ and spreading the integrals on the right side of the graph $\Gamma$, come to the final evaluation of expressions $\left.\sum_{\zeta \in \partial \Gamma} \sigma u^{2}(x, t)\right|_{x=x_{\zeta} \subset \zeta}$ :

$$
\left.\sum_{\zeta \in \partial \Gamma} \sigma u^{2}(x, t)\right|_{x=x_{\zeta} \subset \zeta} \leqslant \epsilon_{\delta}|\sigma| \int_{\Gamma}\left(\frac{\partial u(x, t)}{\partial x}\right)^{2} d x+4|\sigma| \int_{\Gamma} u^{2}(x, 0) d x+4|\sigma| t \int_{\Gamma_{t}}\left(\frac{\partial u(x, t)}{\partial t}\right)^{2} d x d t,
$$

and it means

$$
\left.\sum_{\zeta \in \partial \Gamma} \sigma u(x, 0)^{2}\right|_{x=x_{\zeta} \lessdot \zeta} \leqslant \epsilon_{\delta}|\sigma| \int_{\Gamma}\left(\frac{\partial u(x, 0)}{\partial x}\right)^{2} d x+4|\sigma| \int_{\Gamma} u^{2}(x, 0) d x,
$$

where as $\epsilon_{\delta}$ you can take any small positive number by selecting $\delta$. The second value (9) after integration along $\Gamma$ takes the form

$$
\begin{gathered}
\left.\int_{\Gamma} u^{2}(x, t) d x \leqslant 2 \int_{\Gamma} u^{2}(x, 0) d x+2 \int_{\Gamma} \int_{0}^{t} \frac{\partial u(x, \tau)}{\partial \tau} d \tau\right)^{2} d x \leqslant \\
\leqslant 2 \int_{\Gamma} u^{2}(x, 0) d x+2 t \int_{\Gamma_{t}}\left(\frac{\partial u(x, t)}{\partial t}\right)^{2} d x d t \leqslant 2 \int_{\Gamma} u^{2}(x, 0) d x+2 t \int_{0}^{t} y(t) d t .
\end{gathered}
$$

Given the assessment (10), ratio (8) is given to inequality

$$
\begin{gathered}
y(t) \leqslant y(0)-\int_{\Gamma_{t}} 2 b(x) u(x, t) \frac{\partial u(x, t)}{\partial t} d x d t+ \\
+\epsilon_{\delta}|\sigma| \int_{\Gamma}\left(\frac{\partial u(x, t)}{\partial x}\right)^{2} d x+4|\sigma| \int_{\Gamma} u^{2}(x, 0) d x+4|\sigma| t \int_{\Gamma_{t}}\left(\frac{\partial u(x, t)}{\partial t}\right)^{2} d x d t+ \\
+\epsilon_{\delta}|\sigma| \int_{\Gamma}\left(\frac{\partial u(x, 0)}{\partial x}\right)^{2} d x+4|\sigma| \int_{\Gamma} u^{2}(x, 0) d x+2 \int_{\Gamma_{t}} f(x, t) \frac{\partial u(x, t)}{\partial t} d x d t
\end{gathered}
$$

hence,

$$
y(0)+b^{*} \int_{0}^{t} y(t) d t+b^{*} \int_{\Gamma_{t}} u^{2}(x, t) d x d t+
$$




$$
\begin{aligned}
& +\epsilon_{\delta}|\sigma| \int_{\Gamma}\left(\frac{\partial u(x, t)}{\partial x}\right)^{2} d x+4|\sigma| \int_{\Gamma} u^{2}(x, 0) d x+4|\sigma| t \int_{\Gamma_{t}}\left(\frac{\partial u(x, t)}{\partial t}\right)^{2} d x d t+ \\
& +\epsilon_{\delta}|\sigma| \int_{\Gamma}\left(\frac{\partial u(x, 0)}{\partial x}\right)^{2} d x+4|\sigma| \int_{\Gamma} u^{2}(x, 0) d x+2 \int_{\Gamma_{t}} f(x, t) \frac{\partial u(x, t)}{\partial t} d x d t .
\end{aligned}
$$

Add (12) with (11) and, somewhat overstate the right part, we obtain

$$
\begin{gathered}
y(t)+\int_{\Gamma} u^{2}(x, t) d x \leqslant y(0)+b^{*} \int_{0}^{t} y(t) d t+b^{*} \int_{\Gamma_{t}} u^{2}(x, t) d x d t+ \\
+\epsilon_{\delta}|\sigma| \int_{\Gamma}\left(\frac{\partial u(x, t)}{\partial x}\right)^{2} d x+4|\sigma| \int_{\Gamma} u^{2}(x, 0) d x+4|\sigma| t \int_{\Gamma_{t}}\left(\frac{\partial u(x, t)}{\partial t}\right)^{2} d x d t+ \\
\quad+\epsilon_{\delta}|\sigma| \int_{\Gamma}\left(\frac{\partial u(x, 0)}{\partial x}\right)^{2} d x+4|\sigma| \int_{\Gamma} u^{2}(x, 0) d x+ \\
+2 \int_{\Gamma} u^{2}(x, 0) d x+2 t \int_{0}^{t} y(t) d t+2 \int_{\Gamma_{t}} f(x, t) \frac{\partial u(x, t)}{\partial t} d x d t .
\end{gathered}
$$

It follows, that $\left(v(t)=\int_{\Gamma}\left(u^{2}+u_{t}^{2}+a(x) u_{x}^{2}\right) d x\right)$

$$
\begin{gathered}
v(t) \leqslant\left[2+|\sigma|\left(8+\epsilon_{\delta}\right)\right] v(0)+\epsilon_{\delta}|\sigma| \int_{\Gamma}\left(\frac{\partial u(x, t)}{\partial x}\right)^{2} d x+ \\
+2\left[b^{*}+(2|\sigma|+1) t\right] \int_{0}^{t} v(t) d t++2 \int_{0}^{t}\|f(\cdot, t)\|_{2, \Gamma} v^{1 / 2}(t) d t .
\end{gathered}
$$

Let $\omega(t)=\int_{\Gamma}\left(u^{2}+u_{t}^{2}+u_{x}^{2}\right) d x, c=\min \left\{1, a_{*}\right\}, C=\max \left\{1, a^{*}\right\}$, then obviously $\omega(t) \leqslant$ $C \omega(t)$ and from the previous inequality

$$
\begin{gathered}
c \omega(t) \leqslant\left[2+|\sigma|\left(8+\epsilon_{\delta}\right)\right] C \omega(0)+\epsilon_{\delta}|\sigma| C \omega(t)+ \\
+2\left[b^{*}+(2|\sigma|+1) t\right] C \int_{0}^{t} \omega(t) d t+2 C^{1 / 2} \int_{0}^{t}\|f(\cdot, t)\|_{2, \Gamma} \omega^{1 / 2}(t) d t
\end{gathered}
$$

or

$$
\begin{gathered}
\left(c-\epsilon_{\delta}|\sigma| C\right) \omega(t) \leqslant\left[2+|\sigma|\left(8+\epsilon_{\delta}\right)\right] C \omega(0)+ \\
+2\left[b^{*}+(2|\sigma|+1) t\right] C \int_{0}^{t} \omega(t) d t+2 C^{1 / 2} \int_{0}^{t}\|f(\cdot, t)\|_{2, \Gamma} \omega^{1 / 2}(t) d t .
\end{gathered}
$$

Choose the number $\delta$ so that $\epsilon_{\delta}=2\left|\delta-x_{\zeta}\right|<\frac{c}{|\sigma| C}$ (that is $c-\epsilon_{\delta}|\sigma| C>0$ ) and relabel $\Omega(t)=\max _{0 \leqslant \varsigma t} \omega(\varsigma)$, then $(13)$ converted to mean

$$
\begin{gathered}
\left(c-\epsilon_{\delta}|\sigma| C\right) \Omega(t) \leqslant\left[2+|\sigma|\left(8+\epsilon_{\delta}\right)\right] C \omega(0)+ \\
+2\left[b^{*}+(2|\sigma|+1) t\right] t C \Omega(t)+2 C^{1 / 2}\|f\|_{2, \Gamma_{t}} \Omega^{1 / 2}(t)
\end{gathered}
$$

or, given the $\sqrt{\omega(0) / \Omega(t)} \leqslant 1$,

$$
\Omega^{1 / 2}(t) \leqslant \frac{\left[2+|\sigma|\left(8+\epsilon_{\delta}\right)\right]}{c-\epsilon_{\delta}|\sigma| C} C \omega^{1 / 2}(0)+\frac{2\left[b^{*}+(2|\sigma|+1) t\right] t}{c-\epsilon_{\delta}|\sigma| C} C \Omega^{1 / 2}(t)+\frac{2 C^{1 / 2}}{c-\epsilon_{\delta}|\sigma| C}\|f\|_{2, \Gamma_{t}},
$$


from which $t \leqslant \min \left\{t_{*}, T\right\}$, here is $t_{*}$ where is the positive root of the equation $C^{1 / 2} \frac{2\left[b^{*}+(2|\sigma|+1) t\right] t}{c-\epsilon_{\delta}|\sigma| C}=\frac{1}{2}$, get

$$
\Omega^{1 / 2}(t) \leqslant 2 \frac{\left[2+|\sigma|\left(8+\epsilon_{\delta}\right)\right]}{c-\epsilon_{\delta}|\sigma| C} C \omega^{1 / 2}(0)+\frac{4 C^{1 / 2}}{c-\epsilon_{\delta}|\sigma| C}\|f\|_{2, \Gamma_{t}} .
$$

If $t_{*}<\delta$, then, taking as the starting moment $t=t_{*}$, by virtue of the above reasoning for any $t \in\left[t_{*}, \min \left\{2 t_{*}, T\right\}\right] \subset[0, \tau]$ establishes the fairness of inequality

$$
\Omega^{1 / 2}(t) \leqslant 2 \frac{\left[2+|\sigma|\left(8+\epsilon_{\delta}\right)\right]}{c-\epsilon_{\delta}|\sigma| C} C \omega^{1 / 2}\left(t_{*}\right)+\frac{4 C^{1 / 2}}{c-\epsilon_{\delta}|\sigma| C}\|f\|_{2, \Gamma_{t_{*}, t}},
$$

just $t-t_{*}$ satisfy the same criteria above $C^{1 / 2} \frac{2\left[b^{*}+(2|\sigma|+1)\left(t-t_{*}\right)\right]\left(t-t_{*}\right)}{c-\epsilon_{\delta}|\sigma| C} \leqslant \frac{1}{2}$, in here $\Gamma_{t_{*}, t}=$ $\Gamma \times\left(t_{*}, t\right)$, etc.

Thus, for any $t \in[0, T]$ installed a priori assessment for solutions of initial-boundary value problem (1)-(3) in the space $W_{a}^{2}\left(\Gamma_{T}\right)$

$$
\Omega^{1 / 2}(t)=\sqrt{\int_{\Gamma}\left(u^{2}+u_{t}^{2}+u_{x}^{2}\right) d x} \leqslant C_{1}(t) \omega^{1 / 2}(0)+C_{2}(t)\|f\|_{2, \Gamma_{t}},
$$

where is $C_{1}(t)$ and $C_{2}(t)$ defined constant $a_{*}, a^{*}, b^{*}$ and the time $t$.

Thus, proven

Theorem 1. For solutions $u(x, t) \in W_{a}^{2}\left(\Gamma_{T}\right)$ initial-boundary value problem (1)-(3), when you fulfil the assumptions (4) holds a priori assessment (14) for any $t \in[0, T]$.

Remark 2. Ratio (14) is an analogue of the energy inequality for hyperbolic systems (1) with distributed parameters on the graph $\Gamma$, allowing to estimate the norm of the solution $u(x, t)$ in space $W_{a}^{1}\left(\Gamma_{T}\right)$ through the initial data $\varphi(x), \psi(x)$ and external force $f(x, t)$. It is easy to get a similar assessment of the energy norm of solution $u(x, t)$.

The existence of weak solutions. Here are the conditions for the existence of weak solutions $W_{a}^{1}\left(\Gamma_{T}\right)$. Proof of the existence of weak solution uses a special basis is special basis-system of generalized eigenfunctions of the spectral problem in the domain [3]:

$$
-\frac{d}{d x}\left(a(x) \frac{d \phi}{d x}\right)+b(x) \phi=\lambda \phi, \quad\left(a(x) \frac{\partial \phi}{\partial x}+\sigma \phi\right)_{\partial \Gamma}=0,
$$

viz, the problem of identifying many such numbers $\lambda$, each of which corresponds to at least one nontrivial solution $\phi(x) \in W_{a}^{1}(\Gamma)$, satisfies the identity

$$
l(\phi, \eta)+\sum_{\zeta \in \partial \Gamma} \sigma \phi \eta=\lambda(\phi, \eta)
$$

when any function $\eta(x) \in W_{a}^{1}(\Gamma)$. This means the fact that $\phi(x)$ is a generalized eigenfunction of class $W_{a}^{1}(\Gamma)$. Each number $\lambda$ corresponds to at least one nontrivial generalized solution $\phi(x) \in W_{a}^{1}(\Gamma)$ that satisfies the identity $\ell(\phi, \eta)+\sum_{\zeta \in \partial \Gamma} \sigma \phi \eta=\lambda_{n}(\phi, \eta)$ when any function $\eta(x) \in W_{a}^{1}(\Gamma)$ (here and below, $(\cdot, \cdot)$ is the number product in $L_{2}(\Gamma$ ) or $\left.L_{2}\left(\Gamma_{T}\right)\right)$.

Lemma 2. The following statements have statement:

1. Eigenvalues are real and have ultimate multiple. You can arrange them in ascending order of modules: $\left\{\lambda_{k}\right\}_{k \geqslant 1}$; accordingly numbered and generalized eigenfunction: $\left\{\phi_{k}(x)\right\}_{k \geqslant 1}$.

2. The eigenvalues $\lambda_{k}$ are positive, except maybe a finite number first; if $b(x) \geqslant 0$, then the eigenvalues are non-negative. 
3. System of generalized eigenfunctions $\left\{\phi_{k}(x)\right\}_{k \geqslant 1}$ forms an orthogonal basis in space $W_{a}^{1}(\Gamma)$ and $L_{2}(\Gamma)$ (anywhere below $\left\|\phi_{k}\right\|_{L_{2}(\Gamma)}=1$ ).

Conditions for the existence of weak solutions of initial-boundary value problem (1)(3) presents the following theorem.

Theorem 2. Let $\varphi(x) \in W_{a}^{1}(\Gamma), \psi(x) \in L_{2}(\Gamma), f(x, t) \in L_{2,1}\left(\Gamma_{T}\right)$ and assumptions (4). The initial-boundary value problem (1)-(3) has at least one weak solution in space $W_{a}^{1}\left(\Gamma_{T}\right)$.

$\mathrm{P}$ r o o f. When proof of the theorem uses method Faedo-Galerkin approximation with the special basis $\left\{\phi_{k}(x)\right\}_{k \geqslant 1}[4,5]$, are approximations $u^{N}(x, t)$ to the weak solution will be sought in the form

$$
u^{N}(x, t)=\sum_{k=1}^{N} c_{k}^{N}(t) \phi_{k}(x)
$$

(functions $c_{k}^{N}(t)$ such that $\left.\frac{d c_{k}^{N}(t)}{d t} \in L_{1}(0, T)\right)$ of the ratios

$$
\begin{gathered}
\int_{\Gamma} \frac{\partial^{2} u^{N}(x, t)}{\partial t^{2}} \phi_{l}(x) d x+\int_{\Gamma}\left(a(x) \frac{\partial u^{N}(x, t)}{\partial x} \frac{\partial \phi_{l}(x)}{\partial x}+b(x) u^{N}(x, t) \phi_{l}(x)\right) d x+ \\
+\left.\sum_{\zeta \in \partial \Gamma} \sigma u^{N}(x, t) \phi_{l}(x)\right|_{x=x_{\zeta} \in \zeta}=\int_{\Gamma} f(x, t) \phi_{l}(x) d x \quad(l=\overline{1, N}), \\
c_{k}^{N}(0)=\varphi_{k}^{N}, \quad \frac{d c_{k}^{N}(0)}{d t}=\int_{\Gamma} \psi(x) \phi_{k}(x) d x \quad(k=\overline{1, N}),
\end{gathered}
$$

where $\varphi_{k}^{N}$ is coefficients of the $\operatorname{sum} \varphi^{N}(x)=\sum_{k=1}^{N} \varphi_{k}^{N} \phi_{k}(x)$, approximating when $N \rightarrow \infty$ the function $\varphi(x)$ in norm $W_{2}^{1}(\Gamma)$. Equality (16) are a system of linear ordinary differential equations of second order in the unknown $c_{k}^{N}(t)(k=\overline{1, N})$. The coefficients of its limited function and the right parts belong to $L_{1}(0, T)$. System (16) uniquely solvable when initial data (17). For approximations $u^{N}(x, t)$ fair the assessment (14). Indeed, by multiplying each of the equations (16) on $\frac{d c_{l}^{N}(t)}{d t}$ and summing on $l$ up 1 from $N$ come to the equality

$$
\begin{gathered}
\int_{\Gamma}\left(\frac{\partial^{2} u^{N}(x, t)}{\partial t^{2}} \frac{\partial u^{N}(x, t)}{\partial t}+a(x) \frac{\partial u^{N}(x, t)}{\partial x} \frac{\partial^{2} u^{N}(x, t)}{\partial t \partial x}+b(x) u^{N}(x, t) \frac{\partial u^{N}(x, t)}{\partial t}\right) d x+ \\
+\left.\sum_{\zeta \in \partial \Gamma} \sigma u^{N}(x, t) \frac{\partial u^{N}(x, t)}{\partial t}\right|_{x=x_{\zeta} \in \zeta}=\int_{\Gamma} f(x, t) \frac{\partial u^{N}(x, t)}{\partial t} d x,
\end{gathered}
$$

from which obtained similar (14) inequality for $u^{N}(x, t)$ (see to compare equality (7) for him and the corresponding inequality (14)), the right part of which by virtue of basis $\left\{\phi_{k}(x)\right\}_{k \geqslant 1}$ in space $W_{a}^{1}(\Gamma)$ is limited to constant, not dependent on $N$ and $t \in[0, T]$. The result is an assessment

$$
\int_{\Gamma}\left(\left(u^{N}(x, t)\right)^{2}+\left(\frac{\partial u^{N}(x, t)}{\partial x}\right)^{2}+\left(\frac{\partial u^{N}(x, t)}{\partial t}\right)^{2}\right) d x \leqslant C^{*}, \quad t \in[0, T]
$$

and thus, after integrating from to on $t$ up 0 from $T$,

$$
\left\|u^{N}\right\|_{W_{2}^{1}\left(\Gamma_{T}\right)} \leqslant C_{1}^{*} .
$$

In force (18) you can choose the subsequence $\left\{u_{i}^{N}\right\}_{i \geqslant 1}$ out of the sequence $\left\{u^{N}\right\}_{N \geqslant 1}$ weak convergence in $W_{2}^{1}\left(\Gamma_{T}\right)$ and evenly on $t \in[0, T]$ in norm $L_{2}(\Gamma)$ to some element $u(x, t) \in W_{a}^{1}\left(\Gamma_{T}\right)$. 
Show that the function $u(x, t)$ is a weak solution of problem (1)-(3). The initial condition $\left.u\right|_{t=0}=\phi(x)$ is true by virtue of convergence $\left\{u^{N_{i}}(x, t)\right\}_{i \geqslant 1}$ to $u(x, t)$ for any $t \in[0, T]$ in $L_{2}(\Gamma)$ and $u^{N_{i}}(x, 0) \rightarrow \phi(x)$ in $L_{2}(\Gamma)$. To prove justice identities (5) for $u(x, t)$ multiply each of the ratios (16) on its function $g_{l}(t) \in W_{2}^{1}(0, T), g_{l}(T)=0$. Let's sum all equality received on $l$ from 1 to $N_{i}$ and integrate on $t$ from 0 to $T$. After this in the first member of the left part will carry out integration by parts, as a result come to identity:

$$
\begin{gathered}
\left(-\frac{\partial u^{N_{i}}(x, t)}{\partial t} \frac{\partial \eta^{N_{i}}(x, t)}{\partial t}+a(x) \frac{\partial u^{N_{i}}(x, t)}{\partial x} \frac{\partial \eta^{N_{i}}(x, t)}{\partial x}+b(x) u^{N_{i}}(x, t) \eta^{N_{i}}(x, t)\right) d x d t- \\
-\int_{\Gamma} \frac{\partial u^{N_{i}}(x, 0)}{\partial t} \eta^{N}(x, 0) d x+\left.\int_{0}^{T} \sum_{\zeta \in \partial \Gamma} \sigma u^{N_{i}}(x, t) \eta^{N_{i}}(x, t) d t\right|_{x=x_{\zeta} \in \zeta}= \\
=\int_{\Gamma_{T}} f(x, t) \eta^{N_{i}}(x, t) d x d t
\end{gathered}
$$

fair for any function $\eta^{N_{i}}(x, t)=\sum_{l=1}^{N} g_{l}(t) \phi_{l}(x)$. Many of these functions $\eta^{N_{i}}$ relabel $M_{N_{i}}$ and move in (19) to the limit on selected above subsequence $\left\{u^{N_{i}}\right\}$, when a fixed function $\eta^{N_{i}} \in M_{N_{i}}$. This will lead to the identity (5) for the ultimate functions $u(x, t) \in W_{a}^{1}\left(\Gamma_{T}\right)$, when any $\eta^{N_{i}} \in M_{N_{i}}$. So as $\bigcup_{i=1}^{\infty} M_{N_{i}}$ dense in $\widetilde{W}_{a}^{1}\left(\Gamma_{T}\right)$, means, (5) will run, when any $\eta(x, t) \in \widetilde{W}_{a}^{1}\left(\Gamma_{T}\right)$, that is $u(x, t)$ a weak solution of initial-boundary value problem (1)(3). The theorem is proved.

Remark 3. In proving the theorem 2 of existence of weak solutions $u(x, t)$ and view the approximation $u^{N}(x, t)$ this decision as a finite sum decompositions (15) on functions $\phi_{k}(x)$ (Faedo-Galerkin method) with the help of a special basis $\left\{\phi_{k}(x)\right\}_{k \geqslant 1}$ the system (16), (17) is built is approximation of the original problem (1)-(3) (formula (15) is approximation of the condition $u(x, t))$. This allows you to get the theorem on approximation (the transition to a finite-dimensional occasion), used in the tasks of an applied character

Conclusion. We investigated the weak solvability of initial-boundary value problem for the hyperbolic equation with distributed parameters on oriented limited graph: the existence of weak solutions of a third boundary value problem, the boundary conditions, which are reduced to a uniform and received the assessment of norm. The results are fundamental in the study of problems of optimal control of evolutionary systems on networks [6-14] and analysis of network commercial mathematical models [15].

\section{References}

1. Ladyzhenskaya O. A. Kraevye zadachi matematicheskoi fiziki [Boundary value problems of mathematical physics]. Moscow, Nauka Publ., 1973, 407 p. (In Russian)

2. Provotorov V. V., Volkova A. S. Nachal'no-kraevie zadachi s raspredelennimi parametrami na grafe [Initial boundary value problems with distributed parameters on the graph]. Voronezh, Nauchnay kniga Publ., 2014, 188 p. (In Russian)

3. Volkova A. S., Provotorov V. V. Obobshhennye reshenija i obobshhennye sobstvennye funkcii kraevyh zadach na geometricheskom grafe [Generalized solutions and generalized eigenfunctions of boundary-value problems on a geometric graph]. Izvestija vysshih uchebnyh zavedenij. Mathematica [Russian Mathematics. Proceeding of Higher Educational Institutions], 2014, vol. 58, no. 3, pp. 3-18. (In Russian) 
4. Volkova A. S., Gnilitskaya Yu. A., Provotorov V. V. On the solvability of boundary-value problems for parabolic and hyperbolic equations on geometrical graphs. Automation and Remote Control, 2014, vol. 75 , no. 2, pp. 405-412.

5. Part A. A. Razrechimost nachal'no-kraevoi zadachi giperbolicheskogo tipa s raspredelennimi parametrami na grafe [Solvability of initial-boundary value problem of hyperbolic type with distributed parameters on the graph]. Management systems and information technologies, 2016, vol. 3, pp. 19-23. (In Russian)

6. Provotorov V. V. Boundary control of a parabolic system with delay and distributed parameters on the graph. Intern. conference "Stability and Control Processes" in memory of V. I. Zubov (SCP). Saint Petersburg, 2015, pp. 126-128.

7. Podvalny S. L., Provotorov V. V. The questions of controllability of a parabolic systems with distributed parameters on the graph. Intern. conference "Stability and Control Processes" in memory of V. I. Zubov (SCP). Saint Petersburg, 2015, pp. 117-119.

8. Provotorov V. V., Provotorova E. N. Sintez optimal'nogo granichnogo upravlenija parabolicheskoi sistemy s zapazdyvaniem i raspredekennemi parametrami na grafe [Synthesis of optimal boundary control of parabolic systems with delay and distributed parameters on the graph]. Vestnik of Saint Petersburg University. Applied Mathematics. Computer Sciense. Control Processes, 2017, vol. 13, iss. 2, pp. 209-224. (In Russian)

9. Provotorov V. V., Provotorova E. N. Optimal control of the linearized Navier-Stokes system in a netlike domain. Vestnik of Saint Petersburg University. Applied Mathematics. Computer Sciense. Control Processes, 2017, vol. 13, iss. 4, pp. 428-441. doi.org/10.21638/11701/spbu10.2017.409 (In Russian)

10. Provotorov V. V. Boundary control of a parabolic system with distributed parameters on a graph in the class of summable functions. Automation and Remote Control, 2015, vol. 76, iss. 2, pp. 318-322.

11. Provotorov V. V., Ryazhskikh V. I., Gnilitskaya Yu. A. Unique weak solvability of a nonlinear initial boundary value problem with distributed parameters in a netlike region. Vestnik of Saint Petersburg University. Applied Mathematics. Computer Sciense. Control Processes, 2017, vol. 13, iss. 3, pp. $264-277$. doi.org/10.21638/11701/spbu10.2017.304

12. Karelin V. V. Shtrafnye funkcii v zadache upravleniea processom nabludeniya [Penalty functions in the control problem of an observation process]. Vestnik of Saint Petersburg University. Series 10. Applied Mathematics. Computer Science. Control Processes, 2010, iss. 4, pp. 109-114. (In Russian)

13. Veremey E. I., Sotnikova M. V. Stabilizaciya plazmy na baze prognoza s ustoichivym lineinym pribligeniem [Plasma stabilization by prediction with stable linear approximation]. Vestnik of Saint Petersburg University. Series 10. Applied Mathematics. Computer Science. Control Processes, 2011, iss. 1, pp. 116-133. (In Russian)

14. Aleksandrov A. Yu., Zhabko A. P. On stability of the solutions of a class of nonlinear delay systems. Automation and Remote Control, 2006, vol. 67, no. 9, pp. 1355-1365.

15. Sidnenko T. I., Sergeev S. M. Modelirovanie dvigenia porozdennogo sprosa na agrarnom rynke $\mathrm{v}$ esloviyah asimmetrii informacii [Modeling movements spawned by the demand for the agricultural market in terms of information asymmetry]. Proceedings of Saint Petersburg State Agrarian, 2015, no. 39, pp. 268-270. (In Russian)

Received: June 27, 2018.

Accepted: December 18, 2018.

Author's information:

Vyacheslav V. Provotorov - Dr. Sci. in Physics and Mathematics, Professor; e-mail: wwprov@mail.ru

Sergei M. Sergeev - PhD in Technics, Associate Professor; sergeev2@yandex.ru

Anna A. Part_-anna_razinkova@mail.ru

\section{Разрешимость гиперболической системы с распределенными параметрами на графе в слабой постановке}

B. В. Провоторов ${ }^{1}$, С. М. Сергеев ${ }^{2}$, А. А. Парт ${ }^{3}$

1 Воронежский государственный университет, Российская Федерация, 394006, Воронеж, Университетская пл., 1

2 Санкт-Петербургский государственный политехнический университет Петра Великого, Российская Федерация, 195251, Санкт-Петербург, ул. Политехническая, 29 
3 Военно-воздушная академия имени профессора Н. Е. Жуковского и Ю. А. Гагарина, Российская Федерация, 394052, Воронеж, ул. Старых Большевиков, 54a

Для цитирования: Provotorov V. V., Sergeev S. M., Part A. A. Solvability of hyperbolic systems with distributed parameters on the graph in the weak formulation // Вестник Санкт-Петербургского университета. Прикладная математика. Информатика. Процессы управления. 2019. Т. 15. Вып. 1. C. 107-117. https://doi.org/10.21638/11702/spbu10.2019.108 (In English)

Исследуется слабая разрешимость начально-краевой задачи для уравнения гиперболического типа с распределенными параметрами на ориентированном ограниченном графе и краевыми условиями третьего рода. Пространственная переменная изменяется на ориентированном ограниченном графе. Дифференциальные соотношения определяются на ребрах графа без концевых точек. Во внутренних узлах графа дифференциальные соотношения заменены обобщенными условиями Кирхгофа (в приложениях - балансными соотношениями). Пространство допустимых слабых решений состоит из функций с носителем на графе, принадлежащих соболевскому пространству и удовлетворяющих условиям сопряжения в «предельном» смысле. Идея анализа начально-краевой задачи остается классической: выбирается функциональное пространство со специальным базисом (система обобщенных собственных функций эллиптического оператора задачи), в котором рассматривается начально-краевая задача; для приближений слабого решения задачи (приближения Фаэдо-Галеркина) устанавливаются априорные оценки типа энергетических неравенств; показывается слабая компактность семейства приближений Фаэдо-Галеркина. Предварительно начально-краевая задача рассматривается в пространстве функций со вторыми обобщенными производными и для такой задачи доказывается аналог энергетического неравенства. Из этого следует: 1) сходимость приближений Фаэдо-Галеркина к искомому решению; 2) аппроксимация исходной задачи конечномерной системой обыкновенных дифференциальных уравнений. Путь аппроксимации исходной задачи конечномерной системой позволяет получить теоремы об аппроксимации и может эффективно применяться в различных задачах прикладного характера. Представлены необременительные в приложениях требования, налагаемые на исходные данные задачи, гарантирующие указанные свойства задачи. Полученные результаты являются основополагающими и при исследовании задач управления (оптимального управления) колебаниями промышленных конструкций. Рассмотренная задача и предложенный подход к ее анализу достаточно часто используются при математическом описании колебательных процессов в сетеподобных технических конструкциях, также при изучении волновых явлений в гидросетях.

Ключевые слова: граф, гиперболическое уравнение, начально-краевая задача, априорные оценки, слабая разрешимость.

Контактная информация:

Провоторов Вячеслав Васильевич - д-р физ.-мат. наук, проф.; wwprov@mail.ru

Сергеев Сергей Михайлович - канд. техн. наук, доц.; -sergeev2@yandex.ru

Парт Анна Александровна - anna_razinkova@mail.ru 